\title{
ESTUDO DE UM CASO DE TRANSBORDAMENTO DO RIBEIRÃO JOSÉ PEREIRA EM ITAJUBÁ - MINAS GERAIS
}

\author{
SILVA, João Pedro Rodrigues da - joao.9174@gmail.com \\ Universidade de São Paulo - USP \\ REBOITA, Michelle Simões - reboita@gmail.com \\ Universidade Federal de Itajubá - UNIFEI
}
MATTOS, Enrique Vieira - enrique.vmattos@gmail.com
Universidade Federal de Itajubá - UNIFEI

LEMES, Murilo da Costa Ruv - murilo.ruv@gmail.com

Universidade Federal de Itajubá - UNIFEI

\begin{abstract}
RESUMO: O município de Itajubá, localizado no sul do Estado de Minas Gerais, é afetado por inundações no período de verão. Um desses episódios ocorreu no dia 24 de janeiro de 2017 e causou o transbordamento do ribeirão José Pereira, localizado próximo ao campus da Universidade Federal de Itajubá (UNIFEI). Como nesse dia precipitou apenas $16 \mathrm{~mm}$ na região do ribeirão, que é um valor baixo para seu nível de enchente, a causa do transbordamento tornou-se de interesse para a população e comunidade científica. Diante desses fatos, o presente estudo tem como objetivo avaliar o ambiente atmosférico e geográfico que contribuiu para a inundação no dia 24 de janeiro de 2017. O referido mês apresentou total de $307 \mathrm{~mm}$, precipitação superior ao valor climatológico e teve no dia 23 o maior total diário de precipitação $\left(57 \mathrm{~mm} \mathrm{dia}^{-1}\right)$ próximo ao ribeirão. Portanto, o período prévio à inundação foi caracterizado por excesso de umidade. Embora no dia 24 tenha precipitado apenas $16 \mathrm{~mm}$, nesse mesmo dia na Serra dos Toledos ocorreu precipitação intensa, sendo a água escoada para o ribeirão José Pereira em função da geografia da região. Portanto, as condições úmidas do mês de janeiro associadas com o escoamento da água proveniente da serra foram os responsáveis pelo transbordamento do ribeirão.
\end{abstract}

Palavras-Chave: Precipitação; Serra dos Toledos; Ribeirão José Pereira; Inundação

STUDY OF A OVERFLOW CASE OF THE RIBEIRÃO JOSÉ PEREIRA IN ITAJUBÁ - MINAS GERAIS

ABSTRACT: Itajubá city is located in the South of Minas Gerais state and is affected by floods during the summer. One of these episodes occurred on January 24, 2017 and was restricted to the overflow of the José Pereira river, located near the campus of the Federal University of Itajubá (UNIFEI). In this day was registered $16 \mathrm{~mm}$ of rain close to the river, which is a low value for its flood level. Therefore, the cause of extravasation has become of interest to the population and scientific community. In this way, the present work aims to evaluate the atmospheric and geographic environment that contributed to the flood on January 24, 2017. This month presented total precipitation higher than the climatological value. The maximum rainfall was registered on January 23 $\left(57 \mathrm{~mm} \mathrm{day}^{-1}\right)$. Therefore, the prior period to flooding was characterized by the presence of significant humidity. Although on the 24th the precipitation was only $16 \mathrm{~mm}$, in this same day in Serra dos Toledos it was more intense, and the water flowed to the José Pereira river due to the geography of the region. Therefore, the humidity accumulation in January with the drainage of the water coming from the mountain were responsible for the ribeirão José Pereira overflow.

Keywords: Precipitation; Serra dos Toledos; José Pereira river; Inundation. 


\section{INTRODUÇÃO}

As atividades humanas estão intimamente ligadas com o meio ambiente e, portanto, com o tempo e clima regional. Conhecer o comportamento atmosférico de uma região é de extrema importância para entender, por exemplo, fatores que causam eventos extremos de precipitação. Esses eventos podem estar associados com precipitação em excesso ou ausência dessa. No primeiro caso, os eventos de chuva intensa podem causar inundações, enchentes e deslizamentos (REBOITA et al., 2016).

$\mathrm{Na}$ região sudeste do Brasil muitos dos eventos extremos chuvosos ocorrem durante o verão, pois é o período úmido do sistema de Monção da América do Sul (REBOITA et al., 2010; MARENGO et al., 2012). A monção se desenvolve sobre regiões continentais de baixas latitudes em resposta ao aquecimento diferencial entre o continente e o oceano (RAO et al., 1996, GRIMM et al., 2005, GARCIA e KAYANO, 2009). Algumas das características do sistema de monção sul americana é a presença dos ventos alísios de nordeste mais intensos do que nos demais períodos do ano, o que favorece o transporte de umidade do oceano Atlântico Tropical Norte para a região norte do Brasil. Essa umidade, em conjunto com a evapotranspiração da floresta Amazônica, é transportada pelos ventos, conhecidos como Jatos de Baixos Níveis (JBN) a leste dos Andes, para o sul e sudeste do país. Além disso, na interação desses sistemas com a convecção local pode se desenvolver uma banda de nebulosidade, entre a Amazônia e o oceano Atlântico, cruzando o sudeste do Brasil, chamada de Zona de Convergência do Atlântico Sul (ZCAS). Esse sistema causa grandes volumes de precipitação na região onde atua (CARVALHO et al., 2004). Como mostrado por Reboita et al. (2017), episódios de ZCAS foram responsáveis por algumas das inundações registradas no município de Itajubá, localizado no sul do Estado de Minas Gerais. Enquanto os estudos como o de Reboita et al. (2017) visam descrever os padrões da atmosfera associados a chuvas extremas no sul de Minas Gerais, outros, como o Marciano et al. (2018) e de Reboita et al. (2019), avaliam as características das bacias hidrográficas na qual recebem a precipitação bem como o nível fluviométrico dos rios.

Para o monitoramento das bacias hidrográficas um dos instrumentos necessários é o pluviômetro (ou pluviógrafo). Esse instrumento realiza medidas in situ do total de precipitação num dado intervalo temporal com alto grau de precisão. Como os pluviômetros realizam medidas pontuais, muitas vezes tornase necessária uma extensa rede de instrumentos para monitorar regiões mais extensas. Uma reduzida quantidade de pluviômetros pode afetar a representatividade espacial da precipitação. Em contrapartida, ferramentas de sensoriamento remoto da atmosfera, como satélites e radares, possuem grande potencial de monitoramento em tempo quase real de algumas variáveis meteorológicas sobre grandes regiões. Desde o lançamento dos primeiros satélites (Série Nimbus), no início da década de 60, até os dias atuais, com a atual geração de satélites Geostationary Operational Environmental Satellite (GOES), tornou-se possível o desenvolvimento de diversos produtos para monitoramento do tempo e do clima (KIDDER e VONDDER HAAR, 1995). A alta resolução dos atuais canais do espectro infravermelho $(2-4 \mathrm{~km})$ desses imageadores tem se mostrado eficazes para monitorar as características físicas dos topos das nuvens e estimativa de precipitação. Porém, estimativas de precipitação ainda mais precisas podem ser realizadas na faixa de micro-ondas pelos radares meteorológicos. Os radares permitem estimar a precipitação em 
três dimensões e sobre uma ampla região (por exemplo, radares Banda-S $(\lambda=3$ $\mathrm{cm}$ ), possuem um alcance de aproximadamente $240 \mathrm{~km}$ ) (RINEHART, 2010), desta maneira, complementam as informações pontuais dos pluviômetros. A utilização em sinergia de informações de pluviômetros, satélites e radares pode ser crucial para o melhor entendimento das características da precipitação numa dada região e para o desenvolvimento de metodologias de mitigação ou minimização de danos causados por chuvas intensas.

No dia 24 de janeiro de 2017 ocorreu um transbordamento do ribeirão José Pereira, localizado próximo ao campus da Universidade Federal de Itajubá (UNIFEI), localizada no sul de Minas Gerais - MG, como nesse dia precipitou apenas $16 \mathrm{~mm}$ na região do ribeirão, que é um valor baixo para seu nível de enchente, a causa do transbordamento tornou-se de interesse para a população e comunidade científica. Portanto, o objetivo desse estudo é avaliar o ambiente atmosférico e geográfico que contribuiu para tal inundação. Como na região de estudo não há uma rede de pluviômetros (e também de outras variáveis ambientais), as informações de precipitação foram obtidas através da estimativa de radar meteorológico.

\section{METODOLOGIA}

\section{1 ÁREA DE ESTUDO}

O município de Itajubá (Figura 1) está localizado no sul do Estado de Minas Gerais (SMG) e possui população de 90.658 habitantes (IBGE, 2010). Com relação às características climáticas, possui clima quente e úmido no verão e temperatura mais amena e seco no inverno, o que pode ser evidenciado através da variável umidade relativa, a qual atinge valores abaixo de $30 \%$ nessa estação do ano (REBOITA et al., 2016). A precipitação anual em Itajubá é de $1458 \mathrm{~mm}$.

No verão, as chuvas intensas e/ou mais fracas por vários dias consecutivos afetam o município e causam enchentes, inundações e alagamentos. Nesse contexto, torna-se importante esclarecer as diferenças entre esses três termos (isto é, enchentes, inundações e alagamentos). A enchente é o termo utilizado para indicar a elevação do nível d'água num canal de drenagem devido ao aumento da vazão, atingindo a cota máxima do canal, porém, sem extravasar. Inundação se refere ao transbordamento das águas de um curso d'água, atingindo a planície de inundação ou área de várzea. Em contrapartida, o alagamento é um acúmulo momentâneo de águas em determinados locais por deficiência no sistema de drenagem. (GOERL e KOBIYAMA, 2005).

A topografia da região de Itajubá é do tipo ondulada-montanhosa, pois cerca de $10 \%$ do território apresenta-se plano, $12 \%$ ondulado e $78 \%$ montanhoso (REBOITA et al., 2014). A leste do município encontra-se a Serra dos Toledos, a qual pertence ao município de Itajubá (Figura 1). Como os resultados serão centralizados na influência da Serra dos Toledos no evento de inundação em estudo, torna-se importante detalhar alguns aspectos geográficos da região (Figuras 2 e 3). Entre o local de transbordamento do ribeirão José Pereira e a Serra dos Toledos há uma distância de aproximadamente $7 \mathrm{~km}$ (Figura 2). Quanto ao perfil longitudinal, o ribeirão encontra-se a cerca de 851 $\mathrm{m}$ de altitude de forma que para leste desse a topografia aumenta sua altura apresentando na Serra dos Toledos altitude de cerca de 1189 m (Figura 3). 
Portanto, há um desnível de $338 \mathrm{~m}$ entre essas duas feições geográficas. Devido ao relevo ser extremamente acidentado, há valores máximos de $49 \%$ e médios de $15,9 \%$ de inclinação, numa distância de apenas $7 \mathrm{~km}$ de extensão, entre o pico da serra e a UNIFEI. A rede hidrográfica da região (Figura 1) mostra afluentes à esquerda da Serra dos Toledos, os quais contribuíram para o escoamento da água para a região da inundação. As informações geográficas foram geradas com o software ArcGIS utilizando dados da base do Instituto Brasileiro de Geografia e Estatística (IBGE).

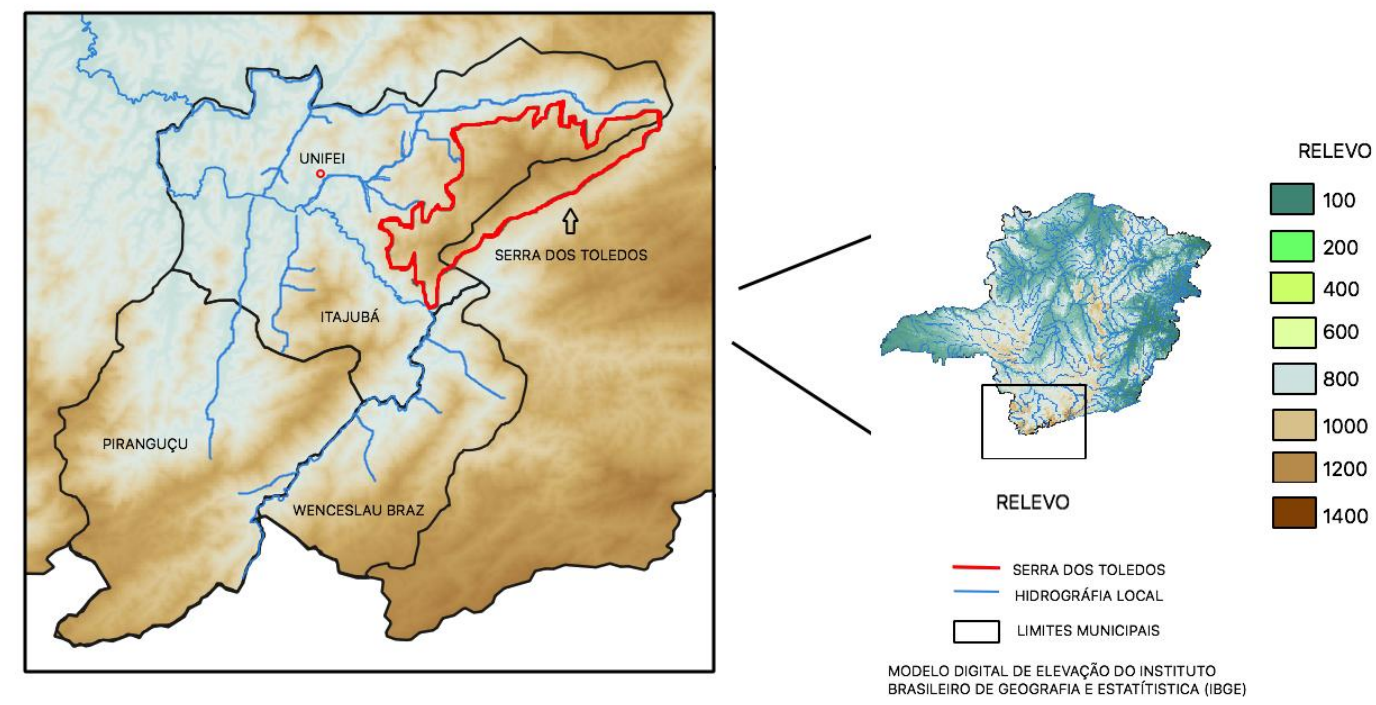

Figura 1 - Localização do município de Itajubá e relevo e hidrografia do sul de Minas Gerais. 


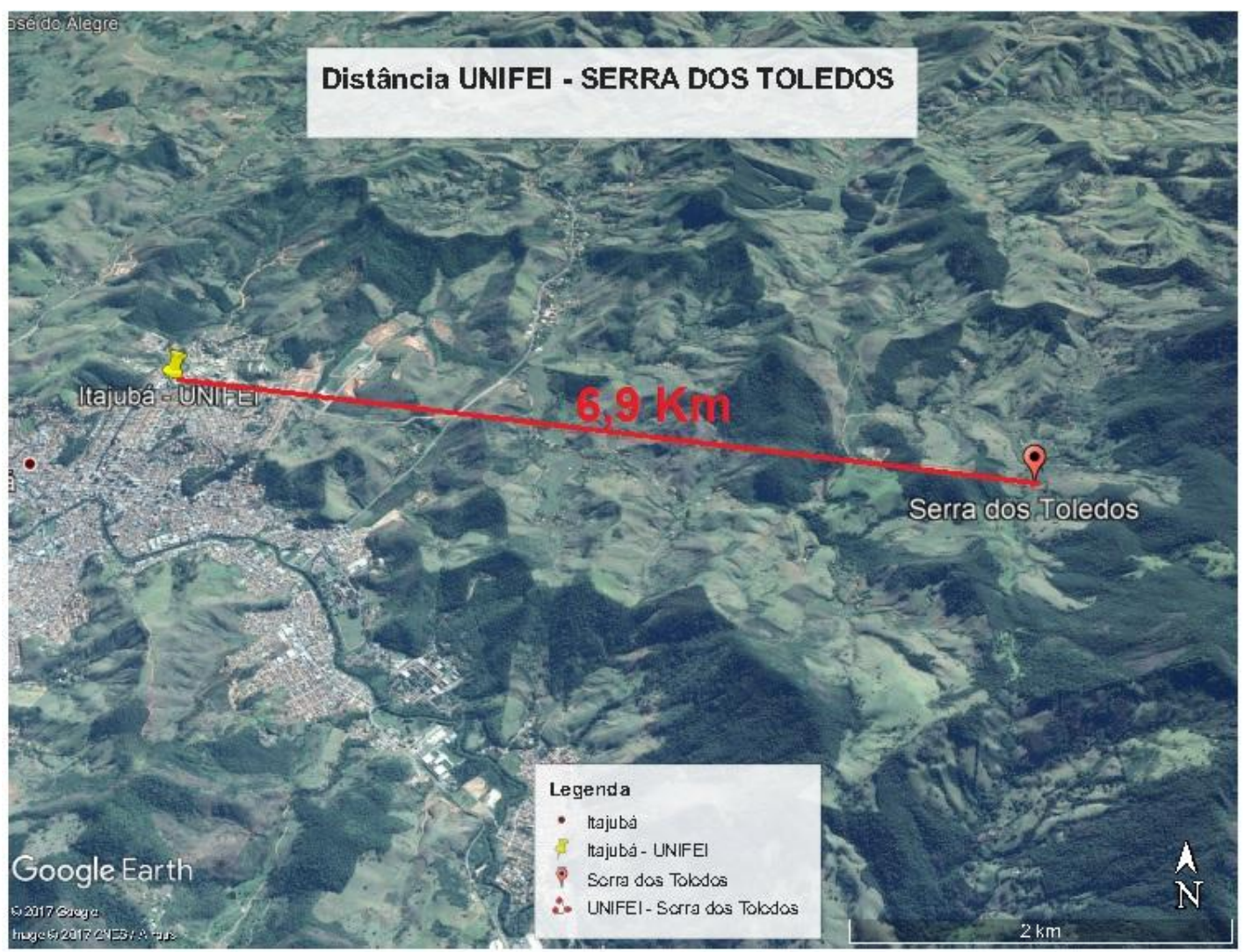

Figura 2 - Distância da UNIFEI até a Serra dos Toledos. Fonte: GOOGLE EARTH.

Altitude $(\mathrm{m})$ Máxima Inclinação: $49 \%$. Inclinação média: 15.9\%

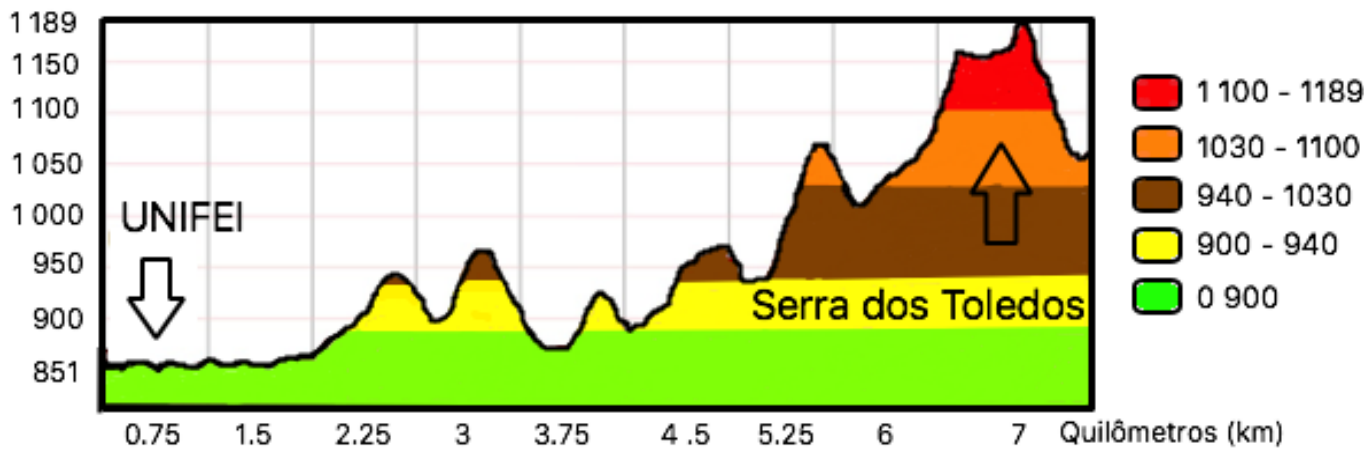

Figura 3 - Perfil de elevação $(m)$ do percurso entre a UNIFEI e Serra dos Toledos. Fonte: GOOGLE EARTH.

\subsection{ANÁLISES}

Inicialmente é mostrado o mapa do transbordamento do ribeirão José Pereira. Para sua elaboração, utilizou-se a técnica de potencial de risco de transbordo, através da calculadora de situações disponibilizada pelo software QGIS. Com uma imagem de satélite sobreposta a do ribeirão e com base em fotografias do dia da inundação, foi calculado um transbordo mínimo de $50 \mathrm{~m}$. Para isso, a declividade foi levada em consideração, representando de maneira 
realista o ocorrido na data da inundação. As fotografias do momento da inundação foram obtidas pelos próprios autores do presente estudo, que acompanharam pessoalmente o evento em estudo. Além disso, também foram utilizadas fotografias obtidas por membros da comunidade.

Na sequência é mostrada a climatologia de precipitação em Itajubá e a evolução diária da precipitação no mês de janeiro de 2017. Para isso, foram utilizados dados de precipitação medidos por um pluviômetro instalado na estação meteorológica da UNIFEI (https://meteorologia.unifei.edu.br/). A descrição do ambiente atmosférico (na escala sinótica) que contribuiu para a precipitação ao longo do mês de janeiro foi realizado com o auxílio das cartas sinóticas de superfície, $850 \mathrm{hPa}, 500 \mathrm{hPa}$ e $250 \mathrm{hPa}$, para o período entre 19 e 24 de janeiro de 2017, obtidas no sítio do Centro de Previsão de Tempo e Estudos Climáticos - CPTEC do Instituto Nacional de Pesquisas Espaciais - INPE (http://www.cptec.inpe.br/). A análise de cartas sinóticas é uma tarefa da área de Ciências Atmosféricas e tem o objetivo de identificar os principais fenômenos meteorológicos na escala espacial de 103 km (AHRENS, 1994) e suas causas atuando numa ampla região. Com relação aos elementos apresentados nessas cartas pode-se destacar os seguintes aspectos: i) carta de superfície mostra a pressão atmosférica ao nível médio do mar, linhas de espessura entre 1000 e $500 \mathrm{hPa}$ (que é a diferença de altura geopotencial entre os dois níveis de pressão) e a localização dos sistemas atmosféricos como cavados, cristas, Zona de Convergência do Atlântico Sul (ZCAS), Zona de Convergência Intertropical (ZCIT), Zona de Convergência de Umidade (ZCOU) e frentes frias, quentes e semi-estacionárias; ii) carta de $850 \mathrm{hPa}$ representa uma altura que já não sofre tanta influência da superfície, sendo possível observar regiões de convergência e divergência do vento; iii) carta de $500 \mathrm{hPa}$ mostra as linhas de corrente e a intensidade do vento na média atmosfera e, por fim, iv) carta de $250 \mathrm{hPa}$ também mostra as linhas de corrente, porém o principal sistema de interesse nessa altura, são os jatos de altos níveis, sendo: o Jato Subtropical, ramo norte do Jato Polar e ramo sul do Jato Polar.

Como já mencionado na introdução, não foi a precipitação no local do ribeirão José Pereira no dia 24 de janeiro de 2017 que causou a inundação, portanto, torna-se importante localizar o local da máxima precipitação na região. Como a região não possui uma densa rede de pluviômetros para descrição espacial da chuva, serão utilizados, no presente estudo, produtos de sensoriamento remoto da atmosfera que abrangem uma larga região. Para isso, foram utilizados os dados de Constante Altitude Plan Position Indicator (CAPPI), de refletividade do radar Banda-S de São Roque Esses dados foram fornecidos pelo CPTEC/INPE. Durante o período de estudo, o radar operou com uma resolução temporal de $10 \mathrm{~min}$, e os CAPPI foram produzidos com resolução espacial horizontal e vertical de $1 \mathrm{~km}$, compreendendo os níveis de $3 \mathrm{~km}$ até 16 $\mathrm{km}$ de altura. A conversão de refletividade para precipitação foi realizada através da aplicação da relação Z-R de Marshall-Palmer (1948), expressa pela seguinte formulação:

$$
\mathrm{Z}=200 * \mathrm{R}^{1,6}
$$


A evolução do campo de precipitação por radar foi realizada acompanhando a sequência de imagens do CAPPI de $3 \mathrm{~km}$ de altura de refletividade. Adicionalmente, torna-se importante avaliar a classificação (convectiva ou estratiforme) da precipitação que produziu o evento sendo estudado. Esta avaliação foi realizada aplicando-se o critério estabelecido por Steiner et al. (1995). Neste método utiliza-se o CAPPI de $3 \mathrm{~km}$ de altura de refletividade como dado principal e um pixel é definido como convectivo quando a refletividade $(Z)$ tem valores maiores que $40 \mathrm{dBZ}$. Caso o pixel não seja classificado como convectivo no passo anterior, porém se sua extremidade de $Z$ excede a $Z$ média de uma região de $11 \mathrm{~km}$ por $11 \mathrm{~km}$ ele será classificado como convectivo. Assim, calcula-se a diferença na refletividade entre o pixel de referência e dos pixels ao redor. Se esta diferença estiver acima do limiar o pixel é classificado como convectivo, caso contrário é classificado como estratiforme.

\section{RESULTADOS}

No dia 24 de janeiro de 2017 foram registrados alagamentos na área central da cidade de Itajubá e inundação no bairro Pinheirinho (Figura 4), devido ao transbordamento do ribeirão José Pereira. Entretanto, nesse dia, precipitou apenas $16 \mathrm{~mm}$ na região, valor que é insuficiente para o extravasamento do ribeirão.
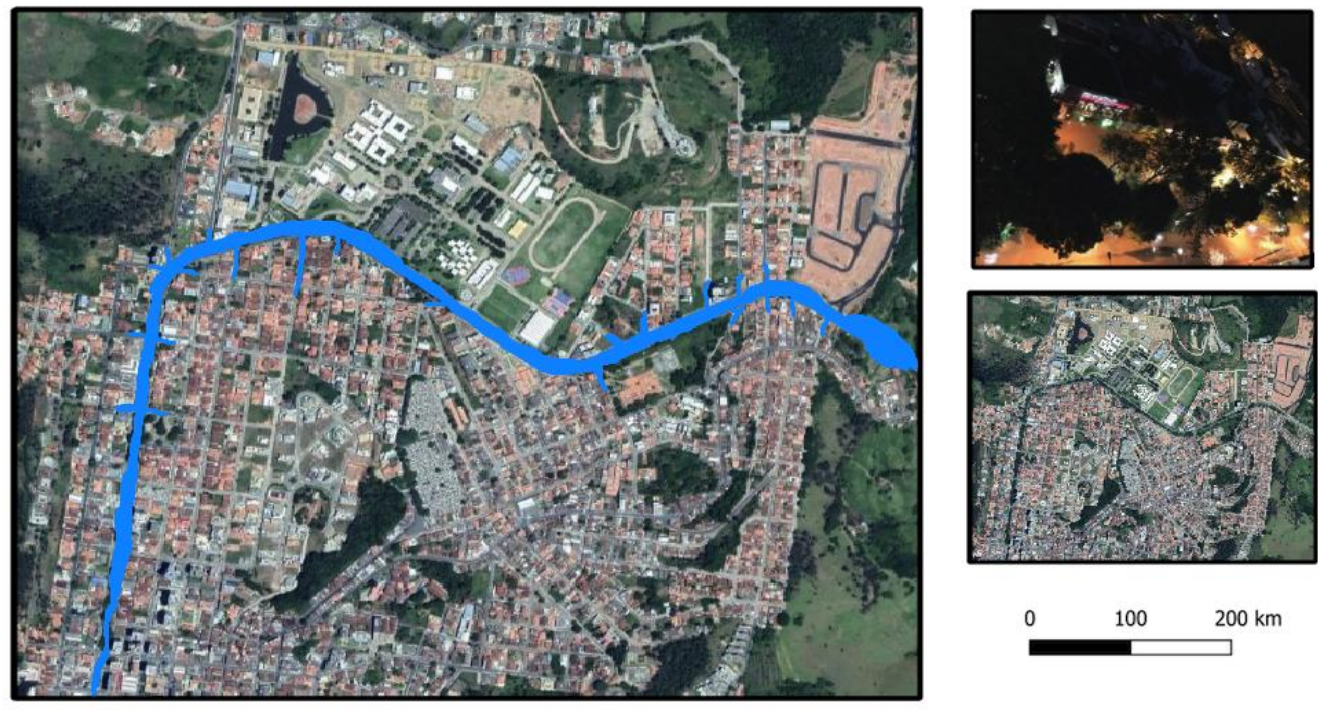

Figura 4 - Imagem de satélite do bairro Pinheirinho mostrando a trajetória do ribeirão José Pereira (azul) e seu extravasamento na avenida BPS. No canto superior direito, o ribeirão localiza-se entre as árvores, mas não é possível identificá-lo, pois, o extravasamento dágua cobriu de maneira praticamente uniforme as duas ruas que estão nas suas margens.

O ciclo mensal de precipitação em Itajubá é caracterizado por maiores totais nos meses de verão e menores nos meses de inverno (Figura 5), como descrito por Reboita et al. (2015). No mês de janeiro de 2017 (Figura 6), a precipitação foi de $307 \mathrm{~mm}$, valor superior ao climatológico, que é de $250 \mathrm{~mm}$. 
Antes do episódio do dia 24, foi registrada precipitação em quase todos os dias de janeiro. O dia 23 foi o que apresentou o maior total diário no mês, isto é, 57 $\mathrm{mm}$ de chuva. No dia 24 a precipitação total foi de $16 \mathrm{~mm}$, bem menor do que no dia anterior, mesmo assim ocorreu inundação em Itajubá. Portanto, outro fator esteve associado a esse evento como será mostrado na sequência.

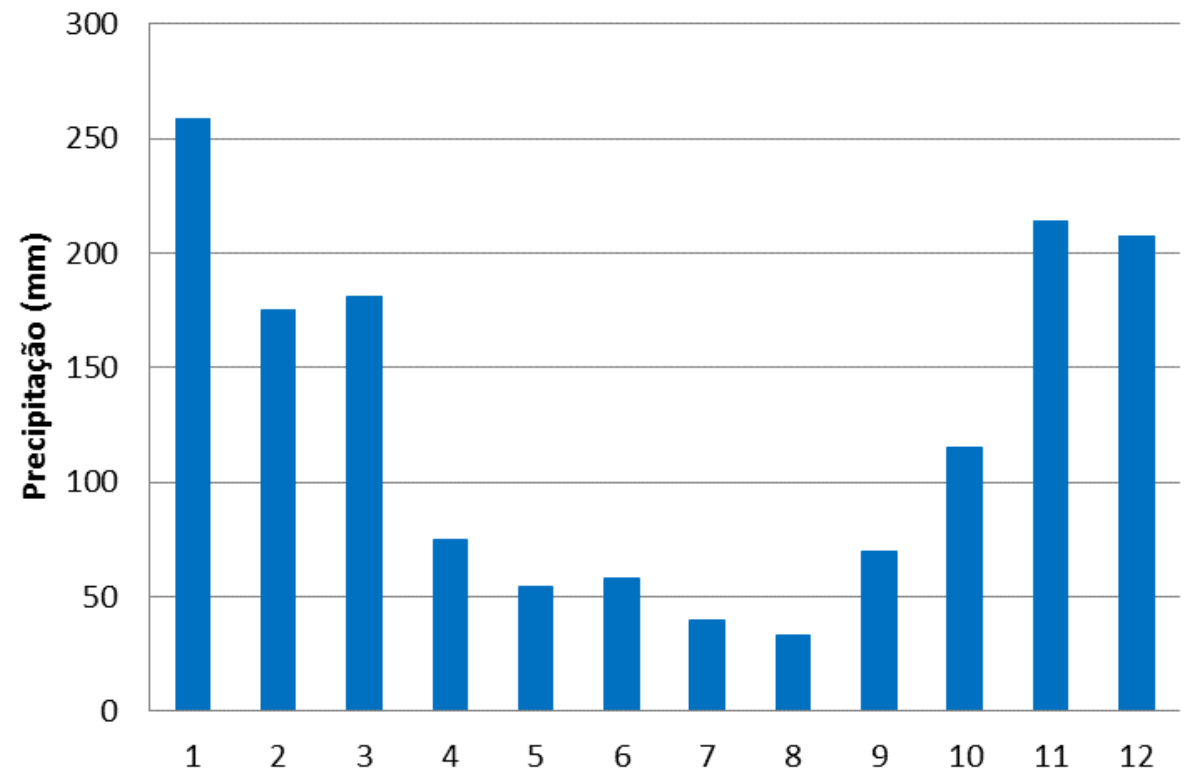

Figura 5 - Ciclo mensal de precipitação no município de Itajubá calculado com dados do período de 2010 a 2018. Fonte: Estação meteorológica do Centro de Previsão e Estudos de Tempo e Clima de Minas Gerais - CEPreMG

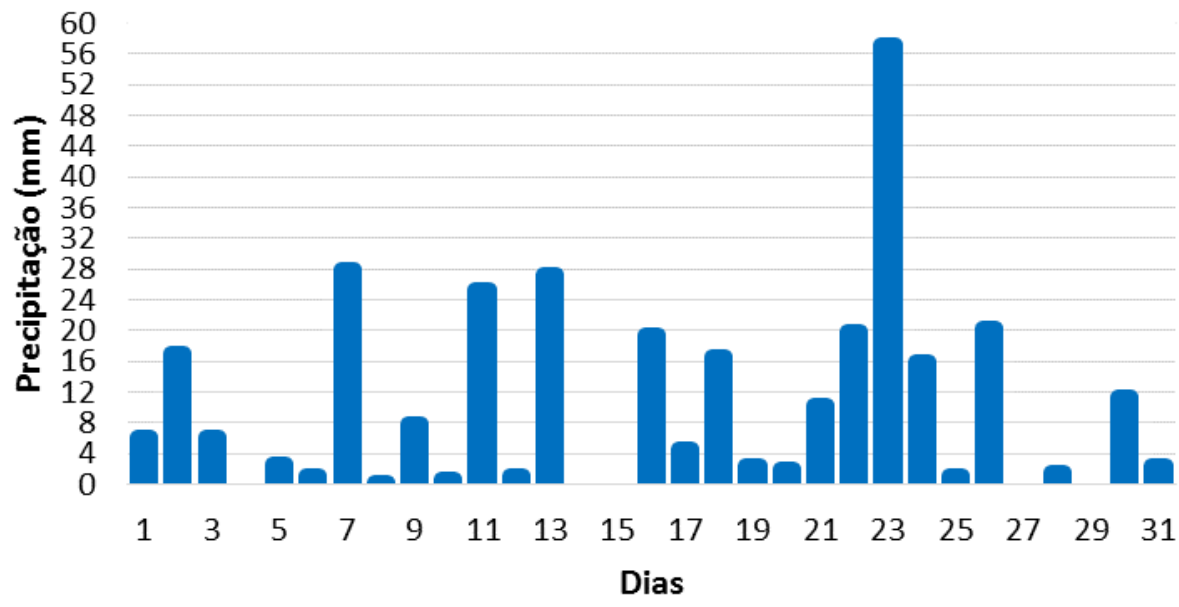

Figura 6 - Precipitação diária no mês de janeiro de 2017. Fonte: Boletim Meteorológico, disponível no site: http://cat-unifei.blogspot.com.br/

A Figura 7 mostra a imagem de satélite no canal do infravermelho do dia 23 de janeiro para exemplificar a posição da ZCAS enquanto a Figura 8 apresenta as cartas sinóticas de $250 \mathrm{hPa}, 500 \mathrm{hPa}, 850 \mathrm{hPa}$ e superfície para os dias 22, 23 e 24 de janeiro de 2017, respectivamente. Os resultados indicam que a precipitação ao longo do mês de janeiro de 2017 ocorreu por fatores associados ao aquecimento da superfície que contribuiu para a convecção local e 
também pela convergência de umidade na região em função da presença de anomalias de baixa pressão sobre o oceano, próximo à costa sul-sudeste do Brasil (Figura 8j-I). Além disso, entre os dias 13 a 16 e entre 18 a 19 de janeiro foi registrada a presença de Zona de Convergência de Umidade sobre o Estado de Minas Gerais (figuras não mostradas) e de 20 a 23 de janeiro, presença de ZCAS, passando entre os estados de São Paulo e Minas Gerais (Figura 8j-k).

O ambiente em que a ZCAS se encontra é formado por um cavado em altos níveis, cujo setor a leste do eixo se encontra sobre a região Sudeste, e por uma crista nas proximidades da região Nordeste (Figura 8a-c). Em médios níveis também se tem a presença do cavado (Figura 8d-f). Esse cavado em níveis médios e altos favorece os movimentos ascendentes na atmosfera que juntamente com a região de baixa pressão em superfície na região costeira criam um ambiente propício para a convergência dos ventos em tal local (Figura $8 \mathrm{~g}-\mathrm{i}$ ). Na região de convergência do escoamento é que se localiza a ZCAS, como mostrado entre os dias 22 e 23 na Figura 8(j-k). No dia 24, não há mais a ZCAS devido a desconfiguração de alguns dos padrões previamente descritos. Entretanto, ainda há convergência do escoamento sobre o Sudeste do Brasil, que é favorecida pela região de menor pressão próximo à costa (Figura 8i).

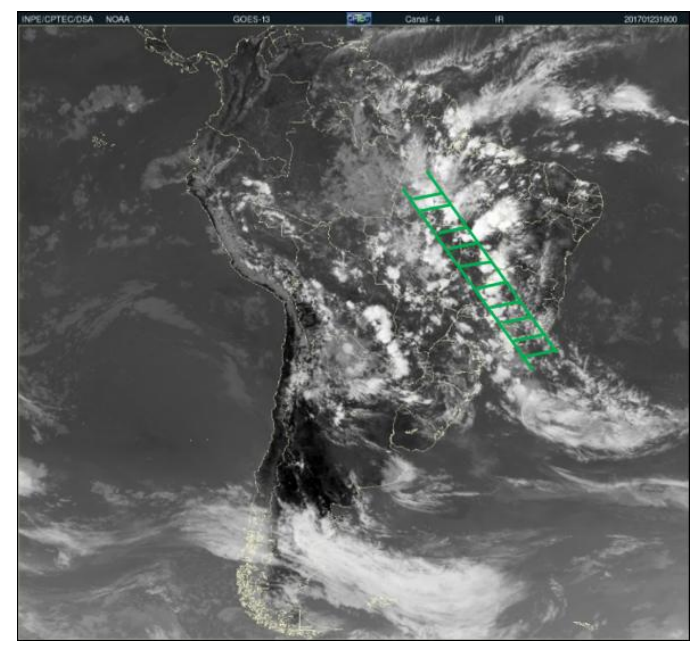

Figura 7 - Imagem do satélite geoestacionário GOES-13 canal infravermelho (10,7 $\mu \mathrm{m})$ do dia 23 de janeiro de 2017 às 1800 UTC com a indicação do sistema ZCAS. Fonte: CPTEC/INPE.

Após a avaliação do padrão da atmosfera, em larga escala, responsável pela precipitação em janeiro, o passo seguinte consiste em identificar o local onde ocorreu precipitação no dia 24, que contribuiu para o transbordamento do ribeirão José Pereira. Como o máximo de precipitação não ocorreu na região da inundação, pode ter ocorrido precipitação intensa em algum outro local que não abrangia a área da estação meteorológica. Para isso, a espacialidade das chuvas foi analisada através dos dados do radar de São Roque (Figura 9). O dia 23 também será analisado para mostrar a atividade convectiva sobre Itajubá, dia em que ocorreu o maior registro de precipitação diária em janeiro de 2017.

A Figura 9 mostra a evolução da refletividade ao longo do dia 23, o que indica a trajetória da nuvem precipitante na região de Itajubá. No dia 23 às 15 UTC (13 horas local) não há presença de eco de radar sobre a região, porém, a 
partir das 17 UTC (Figura 9c), surge uma tempestade que se movimenta para leste e permanece sobre Itajubá. Entre 18 e 18:30 UTC (16 e 16:30 horas local, respectivamente) o sistema atinge sua máxima intensidade, com valores próximos de $55 \mathrm{dBZ}$ a leste do ponto que identifica Itajubá, local que corresponde à Serra dos Toledos (Figura 1). Portanto, a maior intensidade da tempestade esteve na região da Serra do Toledos, com nuvens de grande desenvolvimento vertical e, portanto, mais frias, uma vez que maiores altitudes da atmosfera apresentam menores temperaturas. No horário das 19 UTC (17 horas local) do dia 23, parte da tempestade ainda se mantém sobre Itajubá, mas a partir das 19:30 UTC ela começa a se dissipar, perdendo sua intensidade e diminuindo a precipitação. No dia 24 houve mais um episódio de precipitação na região (Figura $9 d-f$ ), porém de menor intensidade.

As nuvens frias, geralmente possuem a presença de gotas grandes de chuva em sua composição, intensificando ainda mais a precipitação sobre a região. Através da relação $Z-R$, a precipitação relacionada ao maior valor de refletividade na máxima intensidade da tempestade foi de aproximadamente 90 $\mathrm{mm} / \mathrm{h}$. Embora o máximo de precipitação no dia 24 não tenha ocorrido em Itajubá, houve vazão da água para a cidade, visto que a Serra dos Toledos possui maior altitude que Itajubá em aproximadamente 338 metros (Figura 3). Além disso, devido à chuva em quase todos os dias do mês, sugere-se que o solo estivesse bastante úmido e, provavelmente, saturado o que não permitiu a absorção da água no dia 24 (infelizmente, não há registros de água no solo para confirmar a hipótese). 


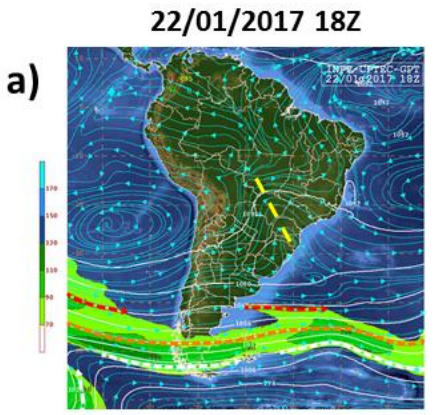

\section{$23 / 01 / 201712 Z$}

b)

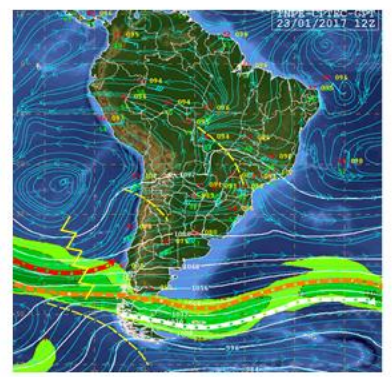

d)

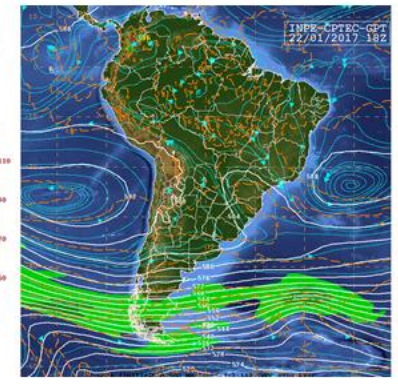

g)

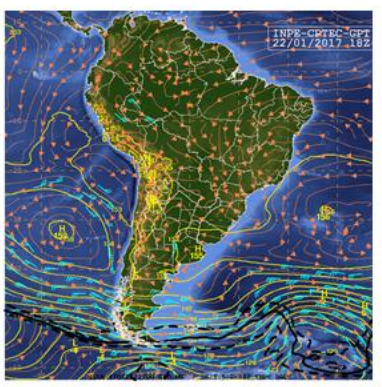

j)

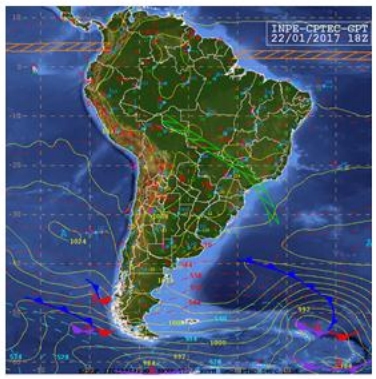

e)

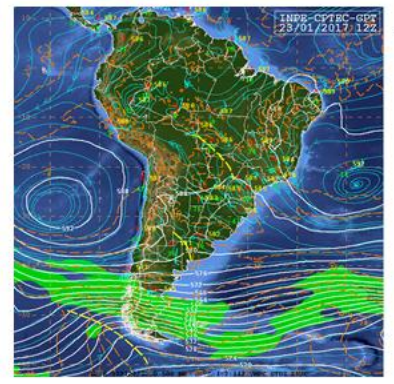

h)

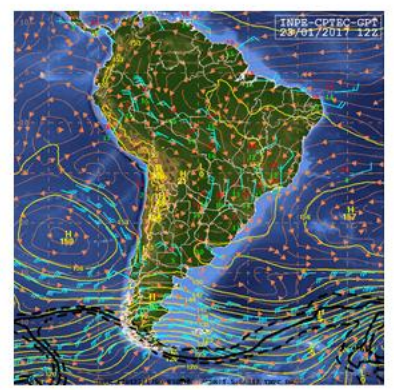

k)

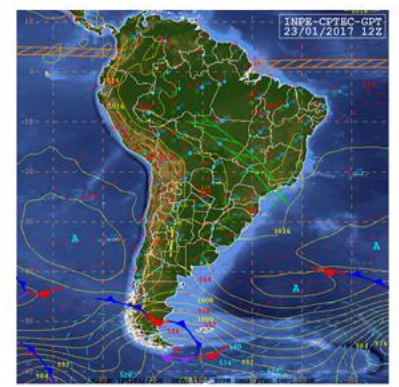

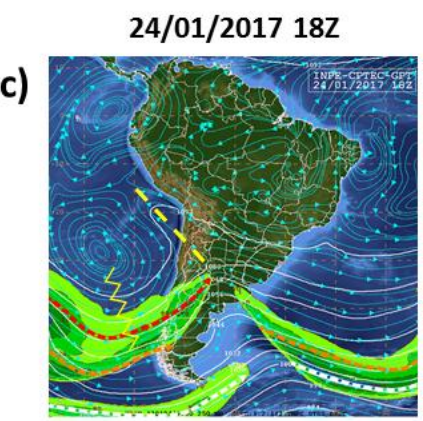

f)

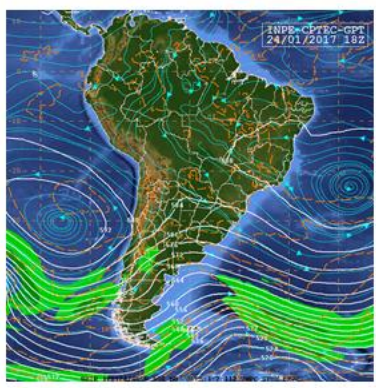

i)

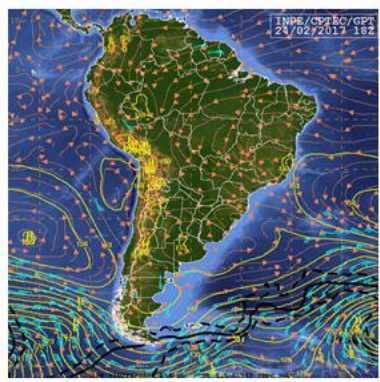

I)

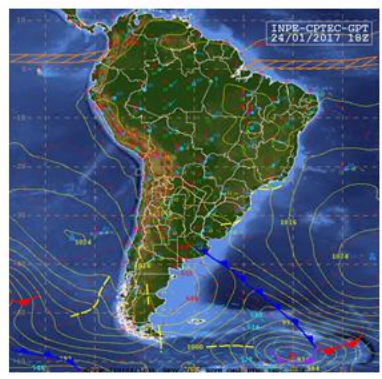

Figura 8 - Cartas sinóticas para os seguintes níveis atmosféricos (linhas): s, a) $250 \mathrm{hPa}$; b) $500 \mathrm{hPa}$; c) $850 \mathrm{hPa}$; d) superfície, e as colunas os dias: 22,23 e 24 de janeiro de 2017. Fonte: CPTEC/INPE.

Na Figura 9, para os horários 18:00 UTC e 18:30 UTC, e na Figura 10 para os horários das 19 UTC e 19:20 UTC, foram realizados cortes verticais na tempestade delimitada na área indicada pela caixa vermelha. Os cortes verticais (Figura 11) permitem identificar a altura e a extensão horizontal das nuvens relacionadas ao evento de precipitação e, também, as regiões mais frias e intensas das tempestades, as quais são destacadas por maiores valores de refletividade. No dia 23 o sistema precipitante apresentou uma extensão horizontal de aproximadamente $20 \mathrm{~km}$ e uma altura de $8 \mathrm{~km}$, com seu centro 
mais intenso com valores próximos à $55 \mathrm{dBZ}$ (Figura 11). Em contrapartida, no dia 24, o sistema apresentou uma menor extensão horizontal, cerca de $12 \mathrm{~km}$ e uma altura de $8 \mathrm{~km}$. Apesar do dia 24 ser o que teve menor total de precipitação (Figura 11), o centro da tempestade estava mais intenso que a do dia 23, com valores próximos a $60 \mathrm{dBZ}$, ou seja, indicando a existência de alta concentração de gotas grandes de chuva e intensa taxa de precipitação. Portanto, na Figura 11, evidencia uma estrutura vertical bem desenvolvida das nuvens precipitantes pertencente a tempestade em estudo com a existência de uma extensa coluna com altos valores de refletividade atingindo até a isoterma de $-10^{\circ} \mathrm{C}$ indicando a existência de fortes correntes ascendentes e largas gotas de água líquida super-resfriada sendo levantadas.

A classificação do tipo da nuvem (estratiforme e convectiva) através da metodologia de Steiner et al. (1995) mostrou que o evento de precipitação do dia 23 e 24 esteve associado a precipitação de caráter convectiva (isto é, associadas a refletividades maiores que $40 \mathrm{dBZ}$ ). 

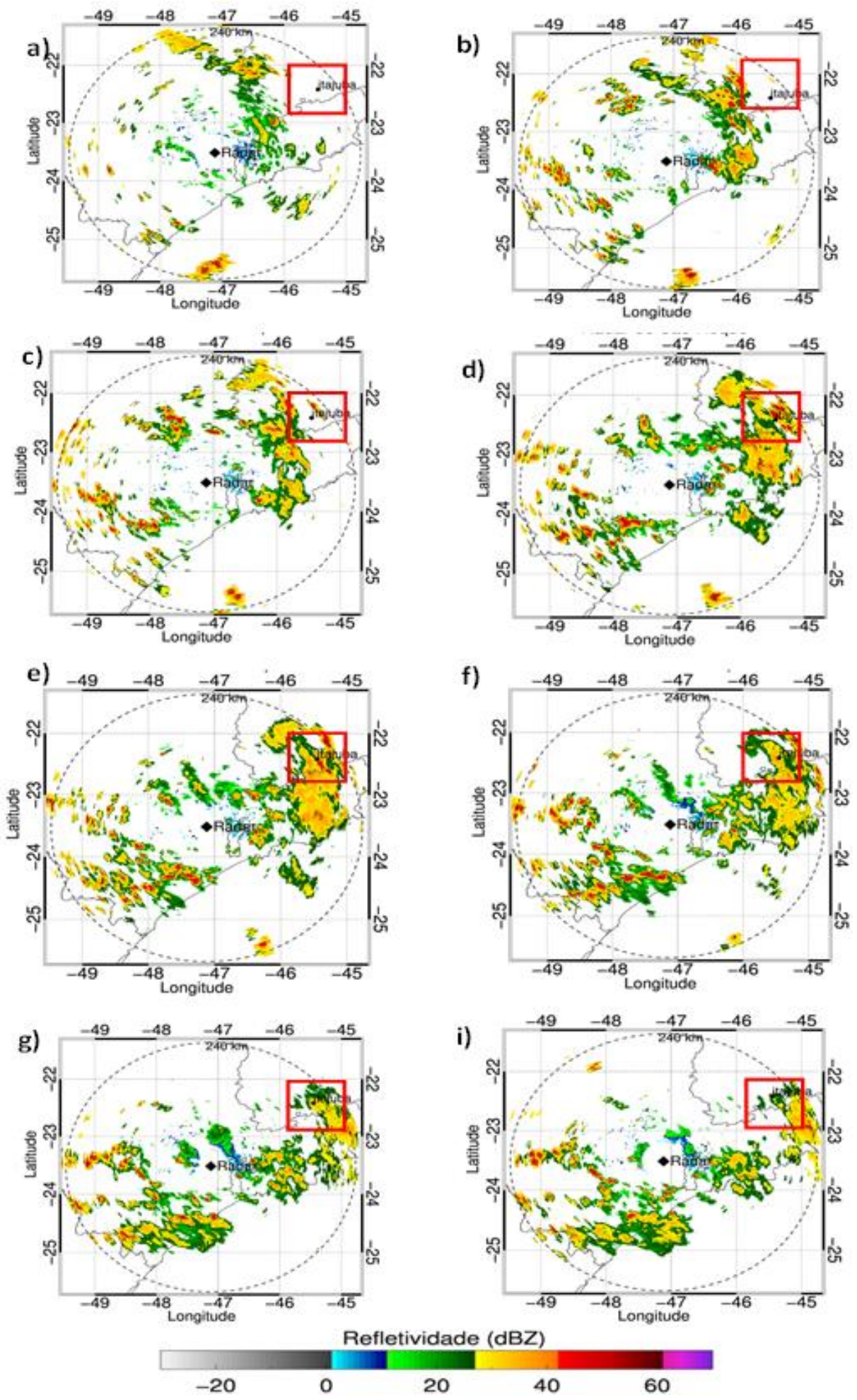

Figura 9 - Constante Altitude Plan Position Indicator (CAPPI) em $3 \mathrm{~km}$ de altura de refletividade do Radar Meteorológico de São Roque - SP para o dia 23 de janeiro de 2017 nos horários: a) 15 UTC, b) 16 UTC, c) 17 UTC, d) 18 UTC, e) 18:30 UTC, f) 19 UTC, g) 19:30 UTC e h) 20 UTC. 

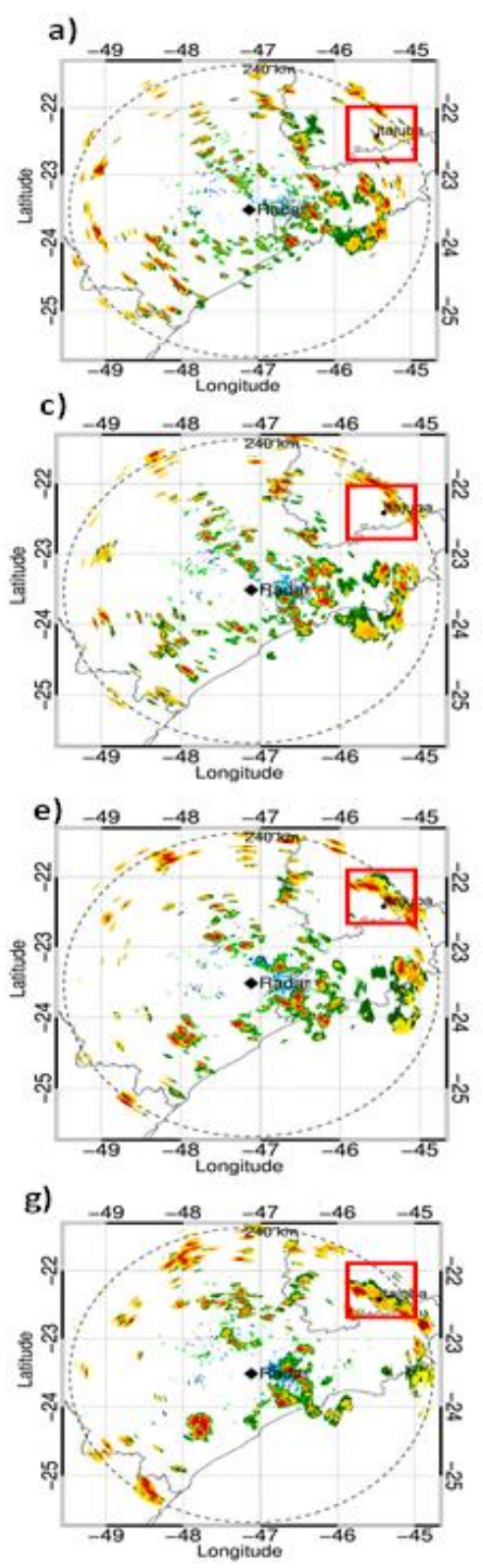
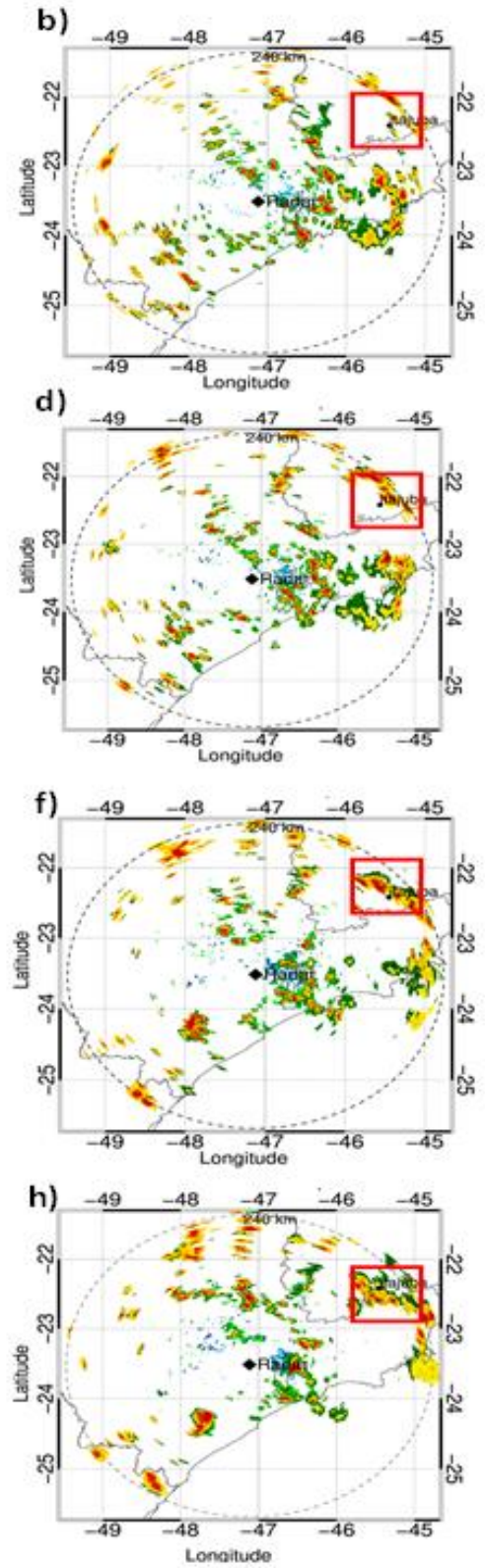

Refletividade (dBZ)

Figura 10 - Constante Altitude Plan Position Indicator (CAPPI) em $3 \mathrm{~km}$ de altura de refletividade do Radar Meteorológico de São Roque - SP para o dia 24 de janeiro de 2017 nos horários: a) 17:50 UTC, b) 18 UTC, c) 18:20 UTC, d) 18:30 UTC, e) 19 UTC, f) 19:20 UTC, g) 19:40 UTC e h) 20 UTC. 

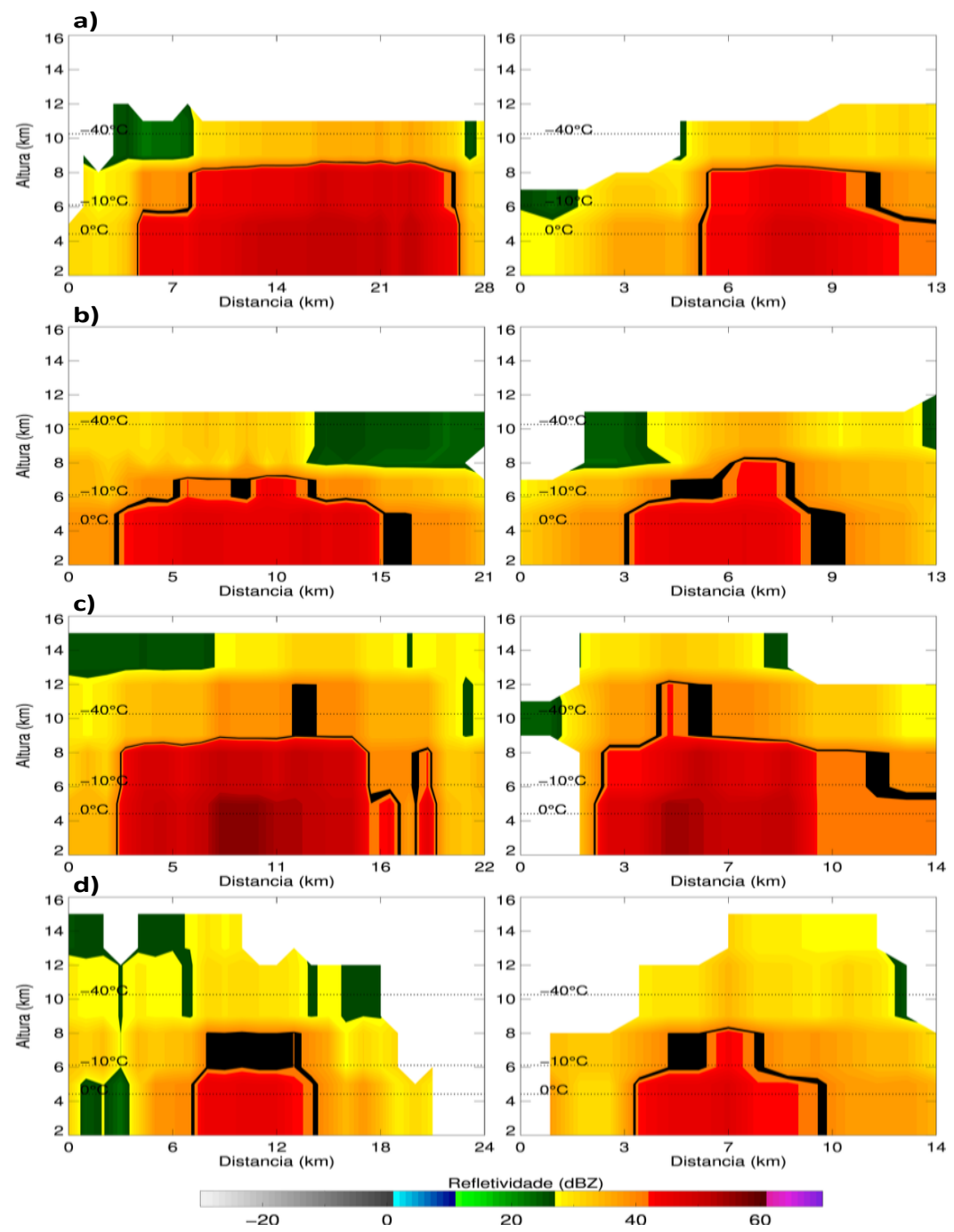

Figura 11 - Corte vertical da variável refletividade (dBZ) da tempestade do dia 23 de janeiro de 2018 nos horários: a) 18:10 UTC b) 18:30 UTC e do 24 de janeiro de 2018 nos horários: c) 19 UTC e d) 19:20 UTC

\section{CONCLUSÕES}

A precipitação do mês de janeiro de 2017 no sul de MG esteve associada tanto à termodinâmica, o que é típico na região durante o verão, quanto à convergência de umidade em função da presença de anomalias de baixa pressão sobre o oceano, próximo à costa sul e sudeste do Brasil. O dia 23 de janeiro apresentou a maior quantidade diária de precipitação em Itajubá, foi registrado aproximadamente $57 \mathrm{~mm}$ dia-1, conforme registro da estação meteorológica da UNIFEI; mas esse não foi o dia do transbordamento do ribeirão José Pereira. Tal fato ocorreu no dia 24 de janeiro em virtude da tempestade ocorrida na Serra dos Toledos, a leste de Itajubá. Como há um desnível de 338 m entre a serra e a região do ribeirão José Pereira, houve escoamento da água precipitada para o ribeirão. Além disso, o solo, provavelmente, estava saturado em função das chuvas ocorridas ao longo do mês de janeiro. Portanto, essas são as causas do transbordamento. 
Através das imagens de radar observou-se a presença de nuvens precipitantes convectivas nos horários em que a tempestade estava mais intensa no dia 24. Esses resultados sugeriram a existência de nuvens precipitantes com grande desenvolvimento vertical, altas concentrações de grandes gotas de chuva e presença de gelo em sua composição, e nuvens estratiformes nos horários em que a tempestade estava se dissipando.

Os resultados deste estudo indicam a importância de expandir estas análises para uma quantidade maior de casos e empregar uma quantidade maior de dados meteorológicos, como por exemplo, uma distribuição espacial maior de pluviômetros e informações a respeito de concentração de gotas medidas por disdrômetros, que é um instrumento utilizado para calcular a quantidade de gotas e velocidade média para várias classes de tamanhos de gotas de chuva. Estudos neste âmbito mostram a importância da aquisição de uma ampla rede de monitoramento de precipitação através estações meteorológicas e ferramentas de sensoriamento remoto da atmosfera visando contribuir para reduzir eventos de desastres naturais.

\section{AGRADECIMENTOS}

Os autores agradecem à Fundação de Amparo à Pesquisa do Estado de Minas Gerais (FAPEMIG) e ao Conselho Nacional de Desenvolvimento Científico e Tecnológico (CNPq) pelo suporte financeiro. Agradecemos também ao Centro de Previsão de Tempo e Estudos Climáticos (CPTEC) do Instituto Nacional de Pesquisas Espaciais (INPE) pelo fornecimento das cartas sinóticas e dados do radar e a Universidade Federal de Itajubá (Unifei) pelos dados da estação meteorológica.

\section{REFERÊNCIAS}

AHRENS, C. DONALD. Meteorology Today: an introduction to weather, climate, and the environment. $5^{\circ}$ ed, West Publishing Company, USA, 1994.

CARVALHO, L. M. V.; JONES, C.; LIEBMANN, B. The South Atlantic Convergence Zone: persistence, intensity, form, extreme precipitation and relationships with intraseasonal activity. J. Climate, 17, p. 88-108, 2004.

KIDDER, S. Q.; VONDDER HAAR, T. H. Satellite meteorology: an introduction. San Diego. Academic Press, $1^{\circ}$ ed. 466p, 1995.

GARCIA, S. R., KAYANO, M. T. Início e fim da estação chuvosa na Bacia Amazônica Central: monitoramento com dados de precipitação estimada pelo satélite TRMM. III Simpósio Internacional de Climatologia, 18-21 outubro, Canela, RS, 2009.

GOERL, R.F.; KOBIYAMA, M. Considerações sobre as Inundações no Brasil. In: XVI SIMPÓSIO BRASILEIRO DE RECURSOS HÍDRICOS, João Pessoa. Anais[...]. Porto Alegre, ABRH, 2005.

GRIMM, A. M.; VERA, C. S.; MECHOSO, C. R. The South American Monsoon System. The Global Monsoon System: Research and Forecast. C.-P. Chang, B. Wang and N.-C. G. Lau, Eds., WMO/TD n. 1266 - TMRP Report n. 70, p. 219238, 2005. 
IBGE - INSTITUTO BRASILEIRO DE GEOGRAFIA E ESTATÍSTICA, 2000. Resultado dos Dados Preliminares do Censo, 2010.

MARENGO, J. A.; LIEBMANN, B.; GRIMM, A. M.; MISRA, V. SILVA DIAS, P. L.; CALVALCANTI, I. F. A.; CARVALHO, L. M. V.; BERBERY, E. H.; AMBRIZZI, T.; VERA, C. S.; SAULO, A. C. ; NOGUES-PAEGLE, J.; ZIPSER, E.; SETH, A. ; ALVES, L. M. Review recente developments on the South American monsoon system. International jornal of Climatology, v. 32, n. 1, p. 1-21, 2012.

MARCIANO, A. G.; BARBOSA, A. A; MONI SILVA, A. P. Estudo de cenários na simulação de eventos de cheias no rio Piranguçu e sua influência no Distrito Industrial de Itajubá-MG. Revista Brasileira de Energias Renováveis, v. 6, n. 1, 2018.

MARSHALL. J.S.; PALMER, W. The distribution of Raindrops with Size. Journal of Atmospheric Sciences, v. 5, n. 4, 1948.

RAO, V. B.; HADA, K. Characteristics of rainfall over Brazil: annual variations and conections with the southern oscillation. Theor. Appl. Climatol. v. 42, p. 8191,1989 .

REBOITA, M.; CORRÊA, M.; RODRIGUES, M.; SILVA, J.P.R. Um balanço do curso de Ciências Atmosféricas no sul de Minas Gerais: Ensino, pesquisa, extensão e benefícios à sociedade. Revista Brasileira de Geografia Física, v.09, n.07, p. 2312-2324, 2016.

REBOITA, M. S.; GAN, M. A.; ROCHA, R. P.; AMBRIZZI, T. Regimes de precipitação na América do Sul: uma revisão bibliográfica. Revista Brasileira de Meteorologia, v. 25, n. 2, p. 185-204, 2010.

REBOITA, M. S.; ASSIREU, A.; SILVA, L. C.; RIOS, N. Evidências de circulação de Brisa Vale-Montanha na Serra da Mantiqueira: Cidade de Itajubá, Mg. Ciência e Natura. V. 36, p.61-71, 2014.

REBOITA, M.S.; RODRIGUES, M; SILVA,L.P.;ALVES, M.A. Aspectos climáticos do estado de Minas Gerais. Revista Brasileira de Climatologia, [S.I.], v. 17, dez. 2015.

REBOITA, M.S.; MARIETTO, D.M.G.; SOUZA, A.; BARBOSA, M. Caracterização atmosférica quando da ocorrência de eventos extremos de chuva na região sul de Minas Gerais. Revista Brasileira de Climatologia, v. 21, p. 20-37, 2017.

REBOITA, M.S; SILVA, B.C.;VITORIANO,M. Modelos de Regressão Aplicados à Previsão De Nível Fluviométrico no Rio Sapucaí em Itajubá-MG. Anuário do instituto de Geociências do Rio de Janeiro, v.3, 2019.

RINEHART, R. E. Radar for Meteorologists. Nevada Missouri, Rinehart Publications, $5^{\circ}$ ed, 482p, 2010.

STEINER, M.; A HOUZE JR, ROBERT; E. YUTER, SANDRA Climatological Characterization of Three Dimensional Storm Structure from Operational Radar and Rain Gauge Data. Journal of Applied Meteorology, v. 34, p. 1978-2008, 1995. 